\title{
Aspergilosis cerebral como causa de lesión cerebral focal asociada SIDA. A propósito de un caso y revisión de la literatura
}

\author{
Emilse Vázquez, Fernando Messina, Gabriela Santiso, Humberto Metta y Ricardo Negroni
}

\footnotetext{
Hospital de Enfermedades Infecciosas F. J. Muñiz, Buenos Aires, Argentina División $B, V I H / S I D A ~(E V, H M, R N)$. Unidad de Micología (FM, GS)

Los autores no presentan conflicto de interés ni fuente de financiamiento.

Recibido: 28 de diciembre de 2016 Aceptado: 8 de agosto de 2017

Correspondencia a: Emilse Vázquez emilsemv@yahoo.com.ar
}

\section{Introducción}

L a aspergilosis invasora es una enfermedad fúngica que afecta característicamente a pacientes inmunocomprometidos. Su incidencia varía entre distintos centros y según el tipo de inmunosupresión. En pacientes con síndrome de inmunodeficiencia adquirida (SIDA) su frecuencia es baja, variando entre 0 y $12 \%$ según diversos autores $^{1-3}$. El órgano principalmente comprometido es el pulmón. La afectación de otros órganos se observa con una frecuencia mucho menor.

Se comunica el caso de un paciente con infección por VIH que presentó una aspergilosis cerebral como causa de compromiso del sistema nervioso central (SNC) asociada al SIDA.

\section{Caso clínico}

Paciente masculino de 41 años con antecedente de infección por VIH cinco años previos a la consulta, sin seguimiento ni tratamiento antirretroviral (TARV). Oriundo de la ciudad de Buenos Aires, se desempeñaba como comerciante en el rubro textil. Realizó un viaje a las sierras de la provincia de Córdoba el mes previo a la consulta, donde realizó actividades recreativas al aire libre. Refirió una historia de fiebre, tos seca, disnea grado III y cefalea de intensidad 2/10 de dos semanas de evolución. Fue internado interpretándose el cuadro como una probable neumocistosis pulmonar. Recibió tratamiento con cotrimoxazol en dosis altas y dexametasona i.v. 24 mg al día. Evolucionó favorablemente de los síntomas respiratorios, sin embargo, persistió con hiperglicemias, las que se manejaron con insulina NPH y se disminuyó progresivamente la dosis de glucocorticosteroides, hasta suspenderlos al décimo día de tratamiento.

En el cuarto día de internación refirió mayor intensidad de la cefalea y horas después presentó un episodio convulsivo. Se realizó una tomografía computarizada (TC) de cerebro sin contraste donde no se observaron alteraciones y una punción lumbar con una presión de apertura de $5 \mathrm{~cm}$ de agua. El examen físico-químico del LCR no presentaba células, con una glucorraquia $62 \mathrm{mg} /$ dl y proteínorraquia $0,46 \mathrm{~g} / \mathrm{l}$. La tinción con tinta china y los cultivos para micobacterias, hongos y bacterias fueron negativos. El estudio con biología molecular, con técnica de RPC para virus herpes simplex 1 y 2, varicela zoster, Epstein Barr, CMV y HHV-6 resultó negativo. Las serologías para toxoplasmosis y enfermedad de Chagas fueron no reactivas. El recuento de linfocitos T CD4 era de 8 céls $/ \mathrm{mm}^{3}$.

Entre el cuarto y décimo día de internación continuó con cefalea de predominio frontal de intensidad 9/10 y vómitos incoercibles. Evolucionó con fiebre por lo que se realizaron hemocultivos para bacterias, micobacterias y hongos, todos con resultados negativos. Ante la sospecha diagnóstica de una criptococosis meníngea se realizó una nueva punción lumbar que no tuvo cambios con respecto a la previa. La antigenorraquia para Cryptococcus resultó negativa.

En el décimo día de internación presentó un episodio autolimitado de disartria y parestesias en la extremidad 


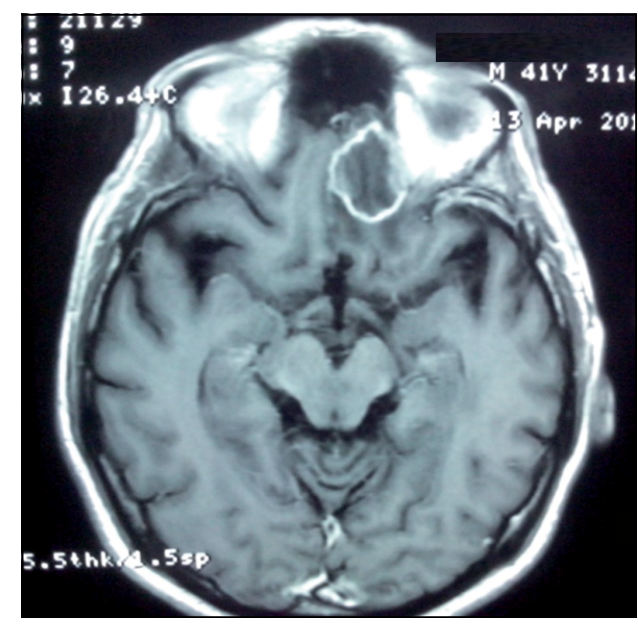

Figura 1. RM de cerebro: se observa lesión hipointensa con realce periférico en anillo.

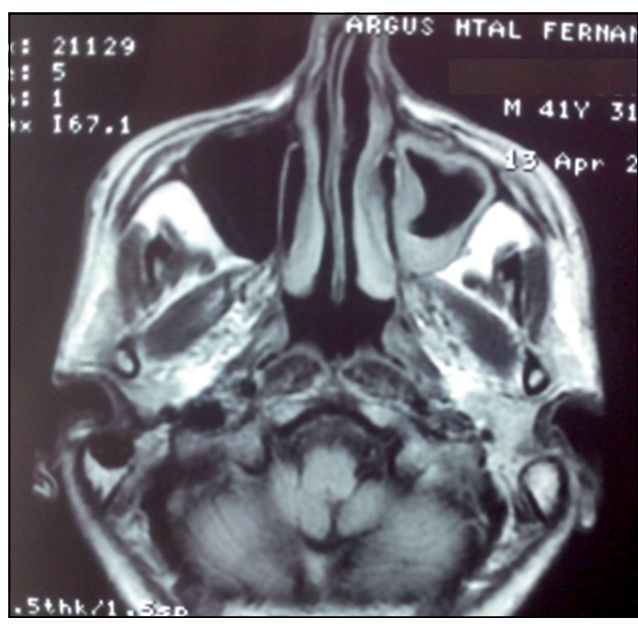

Figura 2. RM de macizo facial: se observa engrosamiento mucoso del seno maxilar izquierdo.

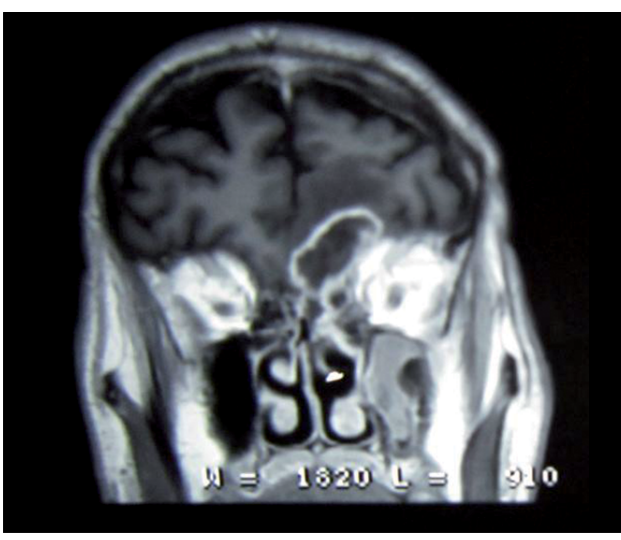

Figura 3. RM de cerebro: se observa en un corte coronal la lesión hipointensa con realce en anillo.

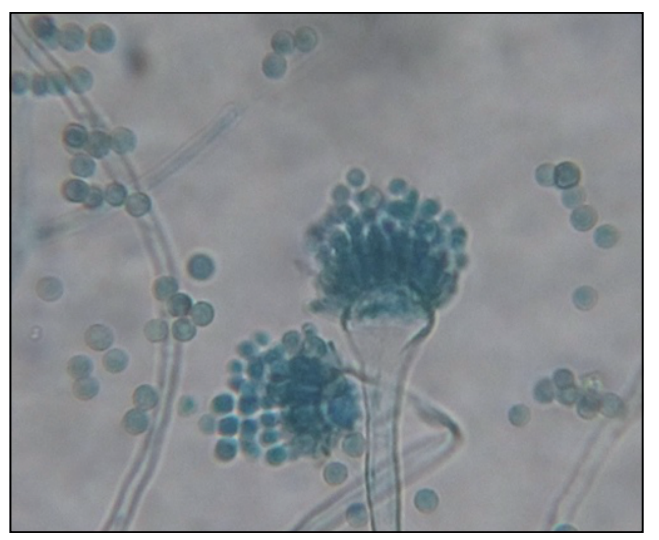

Figura 4. Disociación del cultivo de Aspergillus sección flavi. superior derecha. Se realizó una nueva TC de cerebro con contraste donde se visualizó en topografía frontobasal izquierda una imagen de aspecto nodular con realce en anillo luego de inyectado el contraste intravenoso. Se completó el estudio con una RM de cerebro que evidenció una lesión hipointensa rodeada de un halo hiperintenso compatible con un absceso, asociado a imagenes inflamatorias de las celdillas etmoidales y del seno maxilar izquierdo (Figura 1, 2 y 3 ).

En la evaluación otorrinolaringológica se observó una lesión nasal profunda de la cual se tomó una muestra, observando en el examen en fresco hifas hialinas tabicadas y una cabeza aspergilar. Se inició tratamiento con voriconazol i.v. $6 \mathrm{mg} / \mathrm{kg}$ cada $12 \mathrm{~h}$ el primer día, seguido por $4 \mathrm{mg} / \mathrm{kg}$ cada $12 \mathrm{~h}$. Dos días después se realizó la exéresis neuroquirúrgica del absceso por craneotomía. En el cultivo micológico del material quirúrgico se desarrolló Aspergillus sección flavi (Figura 4). Dicha tipificación se realizó por las características en el cultivo en agar
Czapek y agar Sabouraud a $28^{\circ} \mathrm{C}$, donde se observaron colonias planas, pulverulentas o aterciopeladas, de color verde amarillento brillante. La micromorfología mostró hifas hialinas, conidióforos largos y rugosos, cabezas aspergilares radiadas uni y biseriadas, vesículas esféricas y conidios equinulados. No se realizó tipificación molecular por carecer de ese recurso en el momento de dicho diagnóstico. El paciente evolucionó favorablemente en el postoperatorio inmediato pero falleció una semana después por una neumonía intrahospitalaria que evolucionó a una insuficiencia respiratoria y shock séptico. El óbito temprano del paciente no permitió evaluar la respuesta al tratamiento ni iniciar el tratamiento antirretroviral.

\section{Discusión}

Ante una lesión cerebral focal en un paciente con infección por VIH los diagnósticos diferenciales que se 
plantean en nuestro medio son: toxoplasmosis cerebral, linfoma primario del SNC, tuberculoma, chagoma, nocardiosis e infección por Rhodococcus equi. En enfermos con diabetes mellitus descompensada, como nuestro paciente, la mucormicosis debe ser considerada, especialmente ante una lesión de rápida progresión. Asimismo, deben tenerse presente otros patógenos de menor prevalencia como Aspergillus spp.

Aspergillus spp. es un hongo ubicuo en la naturaleza que crece bien en la tierra, agua, hojas, semillas y material orgánico, por lo tanto la inhalación de conidios es un fenómeno habitual ${ }^{4}$. Sin embargo, la invasión tisular ocurre fundamentalmente en pacientes inmunocomprometidos. La población más afectada son los pacientes sometidos a trasplante de órganos, neutropénicos y los tratados con altas dosis de glucocorticoides. En estos grupos las formas clínicas más comunes son la sinusitis y la neumonía ${ }^{4}$. En la aspergilosis invasora se produce una disrupción de los planos tisulares e invasión vascular por adhesión de componentes de la superficie fúngica a la pared vascular. Esto produce isquemia e infarto de estructuras distales. Si ocurre invasión vascular y/o diseminación hematógena, la aspergilosis puede extenderse más allá del tracto respiratorio y afectar la piel, SNC, hígado, riñones $\mathrm{y}$ otros órganos ${ }^{4}$. El compromiso del SNC puede darse en el contexto de una enfermedad diseminada o como extensión de la localización en senos paranasales, con o sin infiltración orbitaria.

En individuos con infección por VIH la incidencia de la aspergilosis es baja, afectando fundamentalmente a pacientes con recuento de LT CD4 menor de 100 céls $/ \mathrm{mm}^{3}$. El órgano más afectado es el pulmón. El compromiso de SNC se observa en $10 \%$ de quienes presentan aspergilosis diseminada asociada al SIDA ${ }^{1}$.

Se han publicado con anterioridad 40 casos de aspergilosis cerebral en pacientes con infección por $\mathrm{VIH}$ en la literatura médica en idioma inglés ${ }^{2,3,5,6,7,8,9,10}$. El 30\% (12/40) no tenía compromiso de otro órgano fuera del SNC, 35\% (14/40) presentaba concomitantemente compromiso pulmonar y $15 \%(6 / 40)$ presentaba compromiso de órbita (como parte de la presentación rino-sinusoórbito-cerebral). Sólo uno de cada cuatro presentó compromiso de senos paranasales, como en nuestro paciente.

El recuento de LT CD4, en los casos en que pudo determinarse este valor, fue inferior a 100 céls $/ \mathrm{mm}^{3}$. El 22\% (9/40) de los pacientes de esta casuística se encontraba neutropénico y $32 \%$ (13/40) había recibido glucocorticoides previos al inicio de los síntomas. En nuestro caso el paciente tenía un recuento de LT CD4 menor a 50 céls/ $\mathrm{mm}^{3}$ pero en ningún momento presentó neutropenia. El rol de los corticoesteroides en nuestro paciente nos resulta poco claro ya que, si bien la lesión se hizo evidente luego de 10 días de tratamiento con dexametasona a altas dosis, los síntomas neurológicos precedieron a la administración del fármaco. Sin embargo, no se podría descartar que la rápida progresión de la enfermedad pudiera relacionarse con este tratamiento. Nuestro paciente, si bien se desconocía su condición de diabetes mellitus al momento de la internación, presentó valores de hiperglicemias compatibles. En pacientes diabéticos existe un deterioro de la función fagocítica y de la explosión oxidativa ("oxidative burst") de los neutrófilos que podría predisponerlos a la aspergilosis invasora ${ }^{11}$.

En 30 de los 40 pacientes de la casuística se pudo realizar la tipificación del hongo que correspondió a Aspergillus sección fumigati en 27 de los aislamientos. En sólo tres muestras se aisló Aspergillus sección flavi, al igual que en nuestro caso. La prevalencia y distribución de las especies están determinadas, en la mayoría de los casos, por las condiciones geográficas y climáticas, no obstante el tamaño de los conidios de las diferentes especies es trascendental para la presentación clínica. Los conidios de tamaño pequeño $(2-6 \mu \mathrm{m})$ pueden sobrepasar con mayor facilidad el epitelio ciliado y llegar a los alvéolos ${ }^{12}$. Por esta razón Aspergillus sección fumigati es la especie que más frecuentemente se relaciona a aspergilosis pulmonar y Aspergillus sección flavi, que tiene conidios de mayor tamaño, se vincula más frecuentemente a patología de los senos paranasales ${ }^{13}$.

La mortalidad en la serie de 40 casos publicados fue elevada. Sólo cuatro pacientes lograron una sobrevida mayor a ocho meses. Todos recibieron tratamiento con voriconazol y TARV asociado o no a una intervención quirúrgica.

Aspergillus spp. es habitualmente sensible a anfotericina $\mathrm{B}$, voriconazol, itraconazol, posaconazol y equinocandinas. Anfotericina B, especialmente en sus formulaciones lipídicas, era el antifúngico de elección en infecciones diseminadas o graves hasta la publicación, en el año 2002, del ensayo clínico de Herbrecht y cols. donde se demostró una eficacia superior de voriconazol frente a anfotericina B deoxicolato (53\% contra $32 \%$ de respuesta parcial o completa $)^{14}$. Este ensayo ha sido criticado en una revisión de la Cochrane Library, no solo porque la comparación no se realizó con las formulaciones lipídicas de anfotericina, sino porque presentaría sesgos de diseño que le restarían validez a la conclu$\operatorname{sió}^{15}$. Sin embargo, las guías internacionales continúan recomendando voriconazol como primera elección de tratamiento, siempre teniendo en cuenta que no se han realizado trabajos comparativos entre este antifúngico y anfotericina liposomal ${ }^{16}$. En cuanto a las infecciones del SNC, el voriconazol tendría como ventaja su buen pasaje a través de la barrera hematoencefálica con concentraciones en LCR cercanas al $50 \%$ de las plasmáticas. Se ha publicado una revisión de 81 pacientes con aspergilosis en SNC, probadas o probables, en donde la respuesta completa o parcial al tratamiento con voriconazol fue 
de $35 \%$. Un dato de interés en este estudio es que en un análisis multifactorial se asoció el drenaje quirúrgico con una mayor sobrevida ${ }^{17}$.

Si consideramos la sensibilidad microbiológica de las distintas especies debemos tener en cuenta que con el advenimiento de la biología molecular se determinó la existencia de "especies crípticas" las cuales, si bien son muy poco frecuentes ${ }^{18}$, resultan ser más resistentes, al menos in-vitro, a los fármacos antifúngicos ${ }^{19}$. Dentro de la sección flavi la única especie denominada críptica es A. alliaceus, la cual parece ser sensible al voriconazol y resistente a la anfotericina $\mathrm{B}$ y las equinocandinas ${ }^{19}$. Se debe tener en cuenta que a la tipificación de las especies crípticas sólo se llega por técnicas de biología molecular, por lo que cuando no se dispone de esta metodología se debe considerar su existencia por su diferente perfil de sensibilidad a los antifúngicos.

La duración óptima del tratamiento de la aspergilosis del SNC no se ha establecido, debiendo individualizarse según la evolución clínica e imagenológica. Se recomienda mantener el tratamiento hasta la desaparición de los signos radiológicos, con un mínimo de 6 a 12 semanas $^{4}$. La resección quirúrgica debe considerarse si la situación clínica lo permite, especialmente cuando existe compromiso de los senos paranasales ${ }^{16}$. Es fundamental reducir los factores de riesgo, en pacientes con infección por VIH el inicio del TARV es crucial. El curso progresivo y fatal en la mayoría de los pacientes con aspergilosis cerebral asociada al SIDA no permite efectuar recomendaciones sobre la implementación de profilaxis secundaria. Ante la recuperación inmunológica cada caso debe evaluarse de manera individual.

\section{Conclusiones}

La aspergilosis debe tenerse en cuenta como diagnóstico diferencial en pacientes con infección por VIH con recuentos de LT CD4 bajos, que presenten síntomas neurológicos (cefalea, paresias, parestesias, convulsiones, alteración del sensorio, síndrome confusional) y especialmente ante una lesión expansiva cerebral evidente en imágenes del SNC.

El compromiso de los senos paranasales en pacientes inmunocomprometidos siempre debe hacer sospechar una infección fúngica. El compromiso pulmonar simultáneo o la rápida progresión de la enfermedad pueden orientar la sospecha diagnóstica. Sin embargo, la ausencia de afección pulmonar o de senos paranasales no debe desestimar el diagnóstico.

Ante la sospecha de aspergilosis cerebral un diagnóstico rápido y un tratamiento precoz e intensivo podrían mejorar la sobrevida.

\section{Resumen}

La aspergilosis cerebral es una patología infrecuente, pero de elevada mortalidad en pacientes con SIDA. Es importante considerarla entre los diagnósticos diferenciales ante una lesión expansiva cerebral. Se requiere un alto grado de sospecha para poder realizar un diagnóstico precoz. Se presenta el caso de un paciente con infección por VIH con un cuadro neurológico rápidamente progresivo por Aspergillus sección flavi. Se realiza una revisión de 40 casos publicados de aspergilosis cerebral en pacientes con SIDA.

\section{Referencias bibliográficas}

1.- Khoo S H, Denning D W. Invasive aspergillosis in patient with AIDS. Clin Infect Dis 1994; 19 Suppl 1: S41-8.

2.- Mylonakis E, Paliou M, Sax P E, Skolnik P R, Baron M J, Rich J D. Central nervous system aspergillosis in patients with human inmunodefiency virus infection. Report of 6 cases and review. Medicine 2000; 79: 269-80.

3.- Martínez R, Castro G, Machado A A, Moya M J. Primary aspergilloma and subacute invasive aspergillosis in two AIDS patients. Rev Inst Med Trop Sao Paulo 2009; 5: 49-52.

4.- Fortún J, Meije Y, Fresco G, Moreno S. Aspergilosis. Formas clínicas y tratamiento. Enferm Infecc Microbiol Clin 2012; 30: 201-8.

5.- Vidal J E, Dauar R F, Melhem M S, Szeszs W, Pukinskas S R, Coelho J F, et al. Cerebral aspergillus due to Aspergillus fumigatus in AIDS patients: first cultureproven case reported in Brazil. Rev Inst Med Trop Sao Paulo 2005; 47: 161-5.

6.- van Hal S J, Clezy K. Emergence of invasive cerebral aspergillosis in an HIV-positive patient on voriconazole therapy. HIV Med 2005; 6: 45-6.

7.- Gasch O, Fernández N, Ayats J, Santin M. Aspergilosis cerebral en un paciente con infección por VIH: evolución desfavorable a pesar de tratamiento antifúngico combinado. Enferm Infecc Microbiol Clin 2009; 27: 193-4.

8.- Hidron A I, Góngora M C, Anderson A M, Diazgranados C A. Prolonged survival of a patient with AIDS and central nervous system aspergillosis. Med Mycol 2009; 47: 327-30.

9.- Reus-Bañuls S, Bustos Terol S, Caro-Martínez E y Cama-Barbieri J. La aspergilosis cerebral en un paciente con infección por el virus de la inmunodeficiencia humana. Enferm Infecc Microbiol Clin 2012; 30: 350-1.
10.- González-Duarte A, Saniger M, ArispeAngulo K, Gamboa-Domínguez A, García-Ramos G. 47 year-old man with HIV infection and hemiplegia. Brain Pathol 2012; 22: $567-70$.

11.- Chi C Y, Fung C P, Liu C Y. Aspergillus flavus epidural abscess and osteomyelitis in a diabetic patient. J Microbiol Immunol Infect 2003; 36: 145-8.

12.- Quindós G, López J, Santos Pais C, Castaño I, Fernández M y Hernández C. Capítulo 3: Patogenia de las micosis y respuestas defensivas del hospedador. Quindós G. Micología clínica, $1^{\circ}$ ed. Barcelona, España: Elsevier; 2015, p. 35-53.

13.- Pasqualotto A C. Differences in pathogenicity and clinical syndromes due to Aspergillus fumigatus and Aspergillus flavus. Med Mycol 2009; 47 Suppl 1: S261-70.

14.- Herbrecht R, Denning D W, Patterson T F, Bennett J E, Greene R E, Oestmann J W, et al. Voriconazole versus amphotericin $\mathrm{B}$ for 
primary therapy of invasive aspergilosis. $\mathrm{N}$ Engl J Med 2002; 347: 408-15.

15.- Jorgensen K J, Gotzsche P C, Dalboge C S, Johansen H K. Voriconazole versus amphotericin B or fluconazole in cancer patients with neutropenia. Cochrane Database Syst Rev 2014; (2): CD004707.

16.- Patterson T F, Thompson G R 3rd, Denning D
W, Fishman J A, Hadley S, Herbrecht R, et al. Practice Guidelines for the Diagnosis and Management of Aspergillosis: 2016 Update by the Infectious Diseases Society of America. Clin Infect Dis 2016; 63: 433-42.

17.- Schwartz S, Ruhnke M, Ribaud P, Corey L, Driscoll T, Cornely O A, et al. Improved outcome in central nervous system aspergillosis, using voriconazole treatment. Blood 2005; 106: 2641-5.

18.- Nedel W L, Pasqualotto A C. Treatment of infections by cryptic Aspergillus species. Mycopathologia 2014; 178: 441-5.

19.- Howard S J. Multi-resistant aspergillosis due to cryptic species. Mycopathologia 2014; 178 : 435-9. 